\title{
CFPT Regimen
}

National Cancer Institute

\section{Source}

National Cancer Institute. CFPT Regimen. NCI Thesaurus. Code C161945.

A chemotherapy regimen consisting of cyclophosphamide, fluorouracil, prednisone, and tamoxifen that may be used in the treatment of advanced breast cancer. 